\title{
Gamma-Hydroxybutyrate Increases Resting-State Limbic Perfusion and Body and Emotion Awareness in Humans
}

\author{
Oliver G Bosch ${ }^{*, 1,2,6}$, Fabrizio Esposito ${ }^{3,6}$, Michael M Havranek', Dario Dornbierer ${ }^{1,2}$, Robin von Rotz ${ }^{2}$, \\ Philipp Staempfli ${ }^{4}$, Boris B Quednow ${ }^{2,5}$ and Erich Seifritz ${ }^{1,5}$ \\ 'Department of Psychiatry, Psychotherapy and Psychosomatics, Psychiatric Hospital of the University of Zurich, Zurich, Switzerland; ${ }^{2}$ Experimental \\ and Clinical Pharmacopsychology, Department of Psychiatry, Psychotherapy and Psychosomatics, Psychiatric Hospital of the University of Zurich, \\ Zurich, Switzerland; ${ }^{3}$ Department of Medicine, Surgery and Dentistry 'Scuola Medica Salemitana', University of Salerno, Baronissi, Italy; ${ }^{4}$ MR-Center \\ of the Department of Psychiatry, Psychotherapy and Psychosomatics and the Department of Child and Adolescent Psychiatry, Psychiatric Hospital \\ of the University of Zurich, Zurich, Switzerland; ${ }^{5}$ Neuroscience Center Zurich, Research Group Disorders of the Nervous System, University and \\ ETH Zurich, Zurich, Switzerland
}

Gamma-hydroxybutyrate (GHB) is a GHB-/GABA-B receptor agonist inducing a broad spectrum of subjective effects including euphoria, disinhibition, and enhanced vitality. It is used as treatment for neuropsychiatric disorders including narcolepsy and alcohol withdrawal, but is also a drug of abuse. Non-medical users report enhancement of body and emotion awareness during intoxication. However, the neuronal underpinnings of such awareness alterations under GHB are unknown so far. The assessment of regional cerebral blood flow (rCBF) by pharmacological magnetic resonance imaging (PhMRI) enables the elucidation of drug-induced functional brain alterations. Thus, we assessed the effects of GHB (35 mg/kg p.o.) in 17 healthy males on rCBF and subjective drug effects, using a placebo-controlled, doubleblind, randomized, cross-over design employing arterial spin labeling phMRI. Compared to placebo, GHB increased subjective ratings for body and emotion awareness, and for dizziness ( $p<0.01-0.001$, Bonferroni-corrected). A whole-brain analysis showed increased rCBF in the bilateral anterior cingulate cortex (ACC) and the right anterior insula under GHB ( $p<0.05$, cluster-corrected). ACC and insula rCBF are correlated with relaxation, and body and emotion awareness ( $p<0.05-0.001$, uncorrected). Interaction analyses revealed that GHBinduced increase of body awareness was accompanied by increased rCBF in ACC, whereas relaxation under GHB was accompanied by elevated rCBF in right anterior insula $(p<0.05$, uncorrected). In conclusion, enhancement of emotion and body awareness, and increased perfusion of insula and ACC bears implications both for the properties of GHB as a drug of abuse as well as for its putative personalized potential for specific therapeutic indications in affective disorders.

Neuropsychopharmacology (2017) 42, 2 I4I-2I5I; doi:I0.1038/npp.2017.I I0; published online 12 July 2017

\section{INTRODUCTION}

Gamma-hydroxybutyrate (GHB) is an endogenous shortchain fatty acid that is biosynthetically derived from gammaaminobutyric acid (GABA). GHB acts as an agonist on GABA-B receptors (Engberg and Nissbrandt, 1993) and GHB receptors (Benavides et al, 1982). Because of the presence of specific G-protein-coupled high and low affinity binding sites and the specificity of the GHB antagonist NCS-382, GHB was postulated to be a neurotransmitter (Benavides et al, 1982; Snead, 2000). Although physiological concentrations of GHB seem to be insufficient to stimulate GABA-B receptors, this mechanism is discussed to be mainly

\footnotetext{
*Correspondence: Dr OG Bosch, Department of Psychiatry, Psychotherapy and Psychosomatics, Psychiatric Hospital, University of Zurich, Lenggstrasse 3I, Zurich CH-8032, Switzerland, Tel: +4I 443842357, Fax: +4I 44383 4456, E-mail: oliver.bosch@bli.uzh.ch

${ }^{6}$ These authors contributed equally to this work.

Received 24 January 20 17; revised 4 May 20 17; accepted 25 May 20 17; accepted article preview online 31 May 2017
}

responsible for its psychotropic effects when administered orally in humans (Carter et al, 2009). Apart from its direct effects on GHB and GABA-B receptors, GHB has neuromodulator properties on glutamate, dopamine, serotonin, norepinephrine, and acetylcholine transmission (Andresen et al, 2011).

In humans, GHB strongly influences behaviors related to core human autonomic functions such as control of food intake, sexual behavior, and sleep-wake regulation (Bosch and Seifritz, 2016). Some of these behavioral effects are clinically utilized in neuropsychiatric disorders such as narcolepsy, fibromyalgia, and binge-eating syndrome. Moreover, the drug was shown to exert prosocial and prosexual effects and to induce a mixed stimulant-sedative pattern, including euphoria, disinhibition, and enhanced vitality (Abanades et al, 2006; Bosch et al, 2015, 2017), which are instrumentalized by illicit users (Barker et al, 2007; KapitanyFoveny et al, 2015; Lee and Levounis, 2008; Sumnall et al, 2008; Teltzrow and Bosch, 2012). Specifically, non-medical users of the drug reported relaxation, and enhancement of body and emotion awareness, defined as the ability to 
perceive one's own feelings (eg, feeling amazed, satisfied, joyous, or irritated, annoyed, dissatisfied, etc) and physical sensations (eg, experiencing the body schema, heartbeat, breathing, skin, and intestinal sensations etc) (Boden and Thompson, 2015; Cioffi, 1991), often related to the above mentioned prosocial and prosexual effects (Barker et al, 2007; Sumnall et al, 2008; Teltzrow and Bosch, 2012). However, the neuronal underpinnings of such awareness alterations under GHB are unknown so far.

Interoception and emotional self-referential states have crucial roles in healthy functioning and, when impaired, in neuropsychiatric disorders (Paulus and Stein, 2010). Although intensified body and emotion awareness frequently occur in disorders, such as chronic pain in fibromyalgia and dysphoria in depression, also reduction of interoception can be seen in these patients, resulting in feelings of numbness, emptiness, as well as physical and emotional self-alienation (Harshaw, 2015). The anterior cingulate cortex (ACC) and the insula have been suggested as key brain regions in the processing of attentional control, interoceptive, and emotional representations (Lee and Siegle, 2012; Wiebking et al, 2015). Although body awareness seems to be processed in the insula, emotional self-reference and emotional values of interoceptive signals are assumed to be processed in the ACC (Smith and Lane, 2015).

A valid method to measure drug-induced functional brain alterations is pharmacological magnetic resonance imaging (phMRI). Specifically, regional cerebral blood flow (rCBF) changes after drug challenge assessed by arterial spin labeling (ASL) can reveal brain signatures of pharmacological compounds and relationships between brain activity patterns and subjective phenomena (Chen et al, 2011; Detre et al, 2009; Salmeron and Stein, 2002). Two drugs with neuropharmacological resemblances to GHB have been studied using ASL-phMRI: amisulpride and baclofen. Amisulpride is an atypical antipsychotic with antidepressant properties (Racagni et al, 2004), which primarily acts as an antagonist on dopamine D2/D3 receptors, but also as an agonist on GHB receptors (Maitre et al, 1994). Interestingly, amisulpride and $\mathrm{GHB}$ are able to both block and to enhance dopaminergic neurotransmission (Maitre, 1997; Perrault et al, 1997), have antidepressant-like effects in animal models (Papp and Wieronska, 2000; Zerbib et al, 1992) and prosocial effects in humans (Bosch et al, 2015; Saleem et al, 2002). In healthy male adults, 7 days with $200 \mathrm{mg}$ per day led to increased $\mathrm{rCBF}$ in the basal ganglia and decreased $\mathrm{rCBF}$ in the frontal cortex including prefrontal areas, supplementary motor cortex, and bilateral ACC (Viviani et al, 2013). The muscle relaxant baclofen is, like $\mathrm{GHB}$, a GABA derivate and GABA-B receptor agonist that is currently investigated as a treatment of substance use disorders (Agabio et al, 2013; Leone et al, 2010). Both drugs have substantial neurobiological overlaps regarding their metabolomic footprint (Nasrallah et al, 2010), astrocyte activation in the ventral tegmental area (VTA) (Gould et al, 2014), and bi-directional effects on dopaminergic VTA activity (Cruz et al, 2004), most likely due to their shared agonist effect on GABA-B receptors. However, baclofen is selective to GABA-B receptors, whereas GHB also stimulates GHB receptors, and in contrast to baclofen GHB has mood enhancing and prosocial properties (Bosch et al, 2015). Acute (Franklin et al, 2012) and continuous (Franklin et al, 2011) application of 20 and $80 \mathrm{mg}$ per day baclofen in smokers diminished $\mathrm{rCBF}$ in limbic areas, highly overlapping with the amisulpride effects in the medial orbitofrontal cortex (OFC), ACC, and ventral anterior insula. However, subjective psychotropic effects have not been assessed in these studies.

To identify GHB-specific rCBF patterns and their relationships to subjective drug effects, we employed ASL imaging at baseline and 40,65, and $85 \mathrm{~min}$ post challenge with $35 \mathrm{mg} / \mathrm{kg}$ p.o. vs placebo in 19 healthy male subjects. Computerized visual analog scales (VAS) were used to measure subjective appraisals of relaxation, and emotion and body awareness. In addition, dizziness served as marker for side effects. We hypothesized that GHB increases body and emotion awareness, and that these changes are correlated with $\mathrm{rCBF}$ alterations in functionally associated limbic regions such as the ACC and the insula (Smith and Lane, 2015), also identified in previous phMRI studies using amisulpride and baclofen (Franklin et al, 2012; 2011; Viviani et al, 2013).

\section{MATERIALS AND METHODS}

\section{Design and Participants}

A randomized, double-blind, placebo-controlled, balanced, crossed within-subject design was used (Figure 1). Nineteen

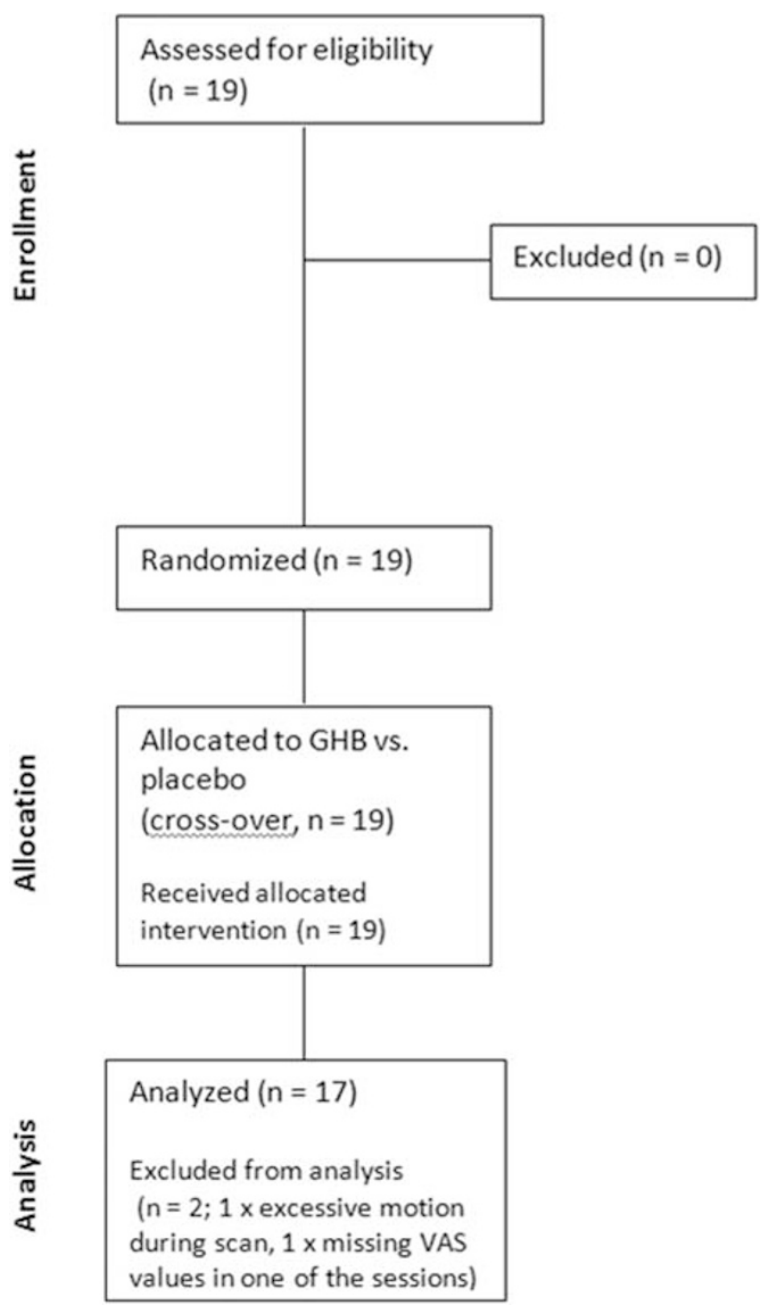

Figure I Randomization flow chart. 
participants took part in the study. They had a mean age of 23.5 years (SD: $\pm 3.6,20-36$ ), a mean verbal intelligence quotient (IQ) of $113.4( \pm 18.4,88-145)$, and a mean weight of $72.2 \mathrm{~kg}( \pm 7.4,59-85)$. All participants were non-smoking, healthy males. They were recruited by online advertising and underwent a medical and psychiatric examination. Exclusion criteria were any DSM-IV psychiatric disorder, neurological disorder, severe medical disease, left-handedness, and illegal drug use (lifetime use $<5$ occasions, with exception of recreational cannabis use $<1$ time per week), latter assessed using the Interview for Psychotropic Drug Consumption (Quednow et al, 2004). Five subjects reported regular but very low cannabis consumption $<1$ time/week (mean 2 times per month) and one subject showed traces of $\Delta 9$-tetrahydrocannabinol in one of two urine tests but was not excluded. A German vocabulary test-the MehrfachwahlWortschatz-Intelligenztest (Lehrl, 2005) - was used to estimate the verbal IQ. Participants had to abstain from drinking alcohol $24 \mathrm{~h}$ before the study days and from drinking caffeinated beverages during the course of the study days. Abstinence from illegal drugs was ensured by semiquantitative drug urine tests (Dimension RXL Max, Siemens, Erlangen, Germany). The study was approved by the Cantonal Ethics Committee of Zurich and by Swissmedic, registered at ClinicalTrials.gov (NCT02342366), and took place at the Psychiatric Hospital of the University of Zurich. All participants provided written informed consent and were financially compensated.

\section{Procedure}

GHB and placebo were applied in two sessions separated by 7 days. On both test days, participants completed an fMRI paradigm (Bosch et al, 2017) on a Philips Achieva 3T whole-body MR-unit equipped with a 32-channel head coil (Philips Medical Systems, Best, The Netherlands) according to a phMRI experimental design as illustrated in Supplementary Figure 1. The experiment started with a T1-weighted anatomical brain scan, a baseline resting-state functional MRI (rsfMRI), and an ASL scan. Subsequently, participants were taken out of the scanner and were orally administered with a single dose of GHB ( $35 \mathrm{mg} / \mathrm{kg})$ or placebo $(t=0 \mathrm{~min})$. A dose of $35 \mathrm{mg} / \mathrm{kg}$ was considered to induce moderate subjective effects in illicit and medical use (Bosch and Seifritz, 2016). As maximal plasma concentration of GHB can be expected after about $40 \mathrm{~min}$ (Liechti et al, 2016), the fMRI paradigm began at $t+30 \mathrm{~min}$. Next, a post-challenge rsfMRI and an ASL scan were acquired at the pharmacologic and subjective peak drug effect $(t=+40 \mathrm{~min})$. Then, participants underwent the first run of the fMRI paradigm (a visual stimulation task, $t=+48 \mathrm{~min}$ ). After that, another rsfMRI and an ASL scan were performed followed by the second run of the fMRI paradigm $(t=+70 \mathrm{~min})$. At the end of the experiment, final rsfMRI and ASL scans were acquired again $(t=+85 \mathrm{~min})$ after which participants were taken out of the scanner and debriefed. Subjective drug effects using VAS $(100 \mathrm{~mm}$ scale, with item name and according statement, eg, 'I am aware of my body', with 'not at all' and 'strongly' on the poles of the scale) assessing general drug effect, sedation, relaxation, stimulation, euphoria, body awareness, emotion awareness, sexual arousal, dizziness, and nausea were applied at $t=-28,+45,+55,+68,+77$, and
+93 min (Abanades et al, 2006; Bosch et al, 2015; Thai et al, 2007). Experimental sessions lasted for $200 \mathrm{~min}$. Here, the GHB effects on VAS for relaxation, body and emotion awareness, and ASL data are presented, whereas the rsfMRI and fMRI data are published elsewhere (Bosch et al, unpublished; Bosch et al, 2017).

\section{MRI Data Acquisition}

FMRI/rsfMRI time series were acquired with a sensitivityencoded single-shot echo-planar imaging sequence (SENSEsshEPI) (Schmidt et al, 2005). The fMRI protocol used the following acquisition parameters: $\mathrm{TE}=35 \mathrm{~ms}, \mathrm{TR}=2500 \mathrm{~ms}$ $\left(=82^{\circ}\right), \mathrm{FOV}=24 \mathrm{~cm}$, acquisition matrix $=80 \times 80$ interpolated to $128 \times 128$, voxel size $=3 \times 3 \times 3 \mathrm{~mm}^{3}, 40$ contiguous axial slices (placed along the anterior-posterior commissure plane), and SENSE factor $R=2.0$.

ASL data were acquired with the pseudo-continuous ASL sequence (Dai et al, 2008) with additional background suppression pulses. Imaging parameters were as follows: TR/ $\mathrm{TE}=4120 / 14 \mathrm{~ms}$, flip angle $=90^{\circ}, \mathrm{FOV}=240 \times 240 \mathrm{~mm}^{2}$, matrix size $=80 \times 80,23$ slices with $7 \mathrm{~mm}$ thickness and no gap, gradient-echo single-shot EPI, SENSE factor $R=2.5$; labeling duration $=1650 \mathrm{~ms}$, post-labeling delay $=1525 \mathrm{~ms}$, number of dynamics (control/tag pairs) $=35$, labeling gap between imaging volumes and labeling slabs $=20 \mathrm{~mm}$. Background suppression was achieved by applying a saturation pulse preceding labeling and by applying two inversion pulses (1680 and $2830 \mathrm{~ms}$ ) after the saturation pulse. For subsequent ASL calibration (see below for absolute rCBF quantification), a proton density (PD) weighted image $(\mathrm{TR} / \mathrm{TE}=10000 / 14 \mathrm{~ms})$ was also acquired with the same position and geometric parameters. Total ASL $(+\mathrm{PD})$ scan duration was $336 \mathrm{~s}$. For structural reference, a 3-dimensional (3D) T1-weighted anatomical scan with the following fast field echo (FFE) sequence was obtained: TR/TE $=9.3 / 4.6 \mathrm{~ms}$, flip angle $=8^{\circ}, 160$ sagittal slices, FOV $=240 \times 240 \mathrm{~mm}^{2}$, voxel size $=1 \times 1 \times 1 \mathrm{~mm}^{3}$.

\section{MRI Data Preprocessing}

2D ASL+PD and 3D T1-weighted data sets were analyzed in BrainVoyager QX version 2.8 (Brain Innovation B. V., Maastricht, The Netherlands). Auxiliary custom scripts were prepared in Matlab version 8.3.0.532 release R2014b (The Mathworks, Natick, MA) to automatically calculate rCBF maps from each preprocessed ASL scan and prepare all rCBF maps for the group-level statistical analyses. The 2D-ASL data preprocessing included 3D rigid body motion correction and spatial smoothing (Gaussian kernel of $6 \mathrm{~mm}$ full width half maximum). After motion correction, the estimated motion parameters were inspected and one subject had to be excluded from subsequent steps due to excessive motion $(>2 \mathrm{~mm})$. For the other 18 subjects, ASL and equilibrium magnetization (M0) images from each individual scan were registered to the corresponding same-session 3D T1-weighted images and then spatially normalized to the Talairach standard space using a 12 parameters affine transformation. The ASL images were resampled to an isometric $3 \mathrm{~mm}$ grid covering the entire Talairach box. To ensure that all ASL scans were normalized to exactly the same locations, the 3D T1-weighted scan of the second 
session was registered to the $3 \mathrm{D}$ T1-weighted of the first session and the same transformation parameters (which were determined from the first 3D T1 scan) were used for normalization of all ASL scans. After registration and normalization, all dynamics were separately averaged over control and label time points. For rCBF quantification at each voxel (absolute $\mathrm{rCBF}$ ) the following model (Alsop et al, 2015; Buxton et al, 1998) was used:

$$
\mathrm{CBF}=\frac{6000 \lambda\left(\mathrm{SI}_{\text {control }}-\mathrm{SI}_{\text {label }}\right) \times e^{\frac{\text { PLD }}{T_{1,} \text { blood }}}}{2 \alpha T_{1, \text { blood }} \times \mathrm{SI}_{\mathrm{PD}}\left(1-e^{-\frac{\tau}{T_{1, \text { blood }}}}\right)}(\mathrm{ml} / 100 \mathrm{~g} / \mathrm{min}),
$$

where $\mathrm{SI}_{\text {control }}$ and $\mathrm{SI}_{\text {label }}$ are the time-averaged signal intensities in the control and labeled images, $\mathrm{SI}_{\mathrm{PD}}$ is the signal intensity of the PD-weighted image, PLD is the postlabeling delay, $\tau$ is the label duration, $T_{1 \text {,blood }}$ is the $T_{1}$ of arterial blood (1664 ms), $\alpha$ is the labeling efficiency (0.95) and $\lambda$ is brain/blood partition coefficient $(0.98 \mathrm{ml} / \mathrm{g})$.

\section{Statistical Analysis}

For the analyses of VAS scales, repeated measures ANOVA with drug (GHB, placebo) and six time points as withinsubject factors were applied using SPSS22.0 for Windows (Armonk, NY: IBM). Greenhouse-Geisser correction and adjusted $p$-values were used in models with more than one degree of freedom in the numerator. Bonferroni-corrected paired $t$-tests were applied for post hoc placebo vs GHB comparisons (six tests). All confirmatory statistical tests were carried out at a significance level of $p<0.05$ (two-tailed, corrected).

For the whole-brain voxel-based analysis of ASL data, all Talairach-normalized rCBF maps from the preprocessed 144 ASL/M0 data sets (18 subjects, 2 sessions, 4 repeated scans) were combined and entered into the analysis of (co)variance (AN(C)OVA) module of BrainVoyager QX. Here, a threeway $(4 \times 2 \times 2)$ mixed-effects ANOVA design was specified with two within-subject factors (scan, treatment), and one between-subject factor (session). Following the experimental design, the factor scan was assigned with four levels (baseline, $t=+40 \mathrm{~min}, t=+70 \mathrm{~min}, t=+85 \mathrm{~min}$ ), the factor treatment with two levels (GHB, placebo) and the factor session had two levels (GHB first, placebo first). All interactions between and among all three factors were also added to the model.

After least square model fitting, to detect any effects of systematic $\mathrm{rCBF}$ changes in relation to time, treatment, and session, the F-statistics for the three-way interaction (scan $x$ treatment $\times$ session) was computed at each voxel, yielding a whole-brain F-map, which was overlaid in pseudo-color onto the average normalized T1 image. To protect against false positives and correct for multiple comparisons, only statistically significant regional effects were displayed for compact clusters surviving the joint application of a voxeland a cluster-level threshold, which were chosen using a non-parametric randomization approach based on Monte Carlo simulations. In detail, an arbitrary (uncorrected) threshold $(p<0.005)$ was initially applied to all voxels; then, a minimum cluster size was set in such a way that an average of $5 \%$ false positive clusters were counted in 1000 randomly generated images to which the same thresholds were applied.
To match the level of 'smoothness' between the calculated F-map and the simulated images, after random number generation at each voxel, the resulting images were spatially filtered with a Gaussian kernel at the full width at half maximum initially estimated from the original ASL images according to (Forman et al, 1995). Apart from interaction effects, no further neuroimaging analyses were performed. In fact, given the experimental design, the main effects of each single ANOVA factor (ie, scan, treatment, or session effects taken independently from each other) were considered as confounds for the 'pure' effect of GHB on CBF coded in the three-way interaction term.

For regions identified in the above analysis, mean regional absolute $\mathrm{CBF}$ values were extracted for each scan, session and subject, and used for region-of-interest (ROI)-based correlation analyses with subjective VAS measures body awareness, emotion awareness, relaxation, and dizziness. One additional subject was excluded from these analyses due to missing VAS values in one of the sessions.

The correlation analyses entailed with a (one-factor) regression analysis and a (two-factor) analysis of covariance analysis (ANCOVA). In the regression analysis, the correlation between $\mathrm{rCBF}$ and VAS changes was assessed after either GHB or placebo challenge across time points. In the ANCOVA analysis, the correlation between $\mathrm{rCBF}$ and VAS changes was assessed independently of the treatment (main effect) and the possible interaction between the different treatment and the observed 'brain-behavior' correlation was also addressed (uncorrected).

All ROI-based analyses were performed in Matlab (The Mathworks, www.matlab.com) using the regression analysis (function: 'regress') and the ANCOVA tools (function: 'aoctool'), which are both part of the built-in statistical toolbox of the Matlab software package. For each postchallenge time point ( $t=40 \mathrm{~min}, t=65 \mathrm{~min}$ or $t=85 \mathrm{~min}$ ), rCBF and VAS differences from the corresponding baseline time point (' $\Delta_{-}$rCBF' and ' $\Delta_{-}$VAS') were calculated and given as input to the regression and ANCOVA functions. In the regression analyses, $\Delta_{-}$VAS values were separately regressed against $\Delta \_$CBF values for each treatment (GHB or placebo) producing separate coefficients of determination (R2) for each time point and treatment. The R2 values were displayed on scatter plots to illustrate the possible modulation of these correlations in different time points and treatments. To further assess the $\mathrm{rCBF} v s \mathrm{VAS}$ correlations independently of the treatment as well as the effect of treatment on these correlations, all $\Delta_{-}$VAS and $\Delta_{-} \mathrm{CBF}$ values from corresponding post-challenge time points in the $\mathrm{GHB}$ and placebo sessions were pooled together and entered into the same ANCOVA model in which the treatment was added as the categorical factor. In this way, besides the correlation, the statistical significance of the change in the slope of the regression line between GHB and placebo sessions was also estimated and reported as an interaction between $\mathrm{rCBF}$ and VAS correlation and treatment (uncorrected).

\section{RESULTS}

\section{Subjective Measures}

In drug $\times$ time $(2 \times 6)$ ANOVAs, significant time effects were found for dizziness $\left(\mathrm{F}_{1,15}=5.98, p<0.01\right)$, drug effects 

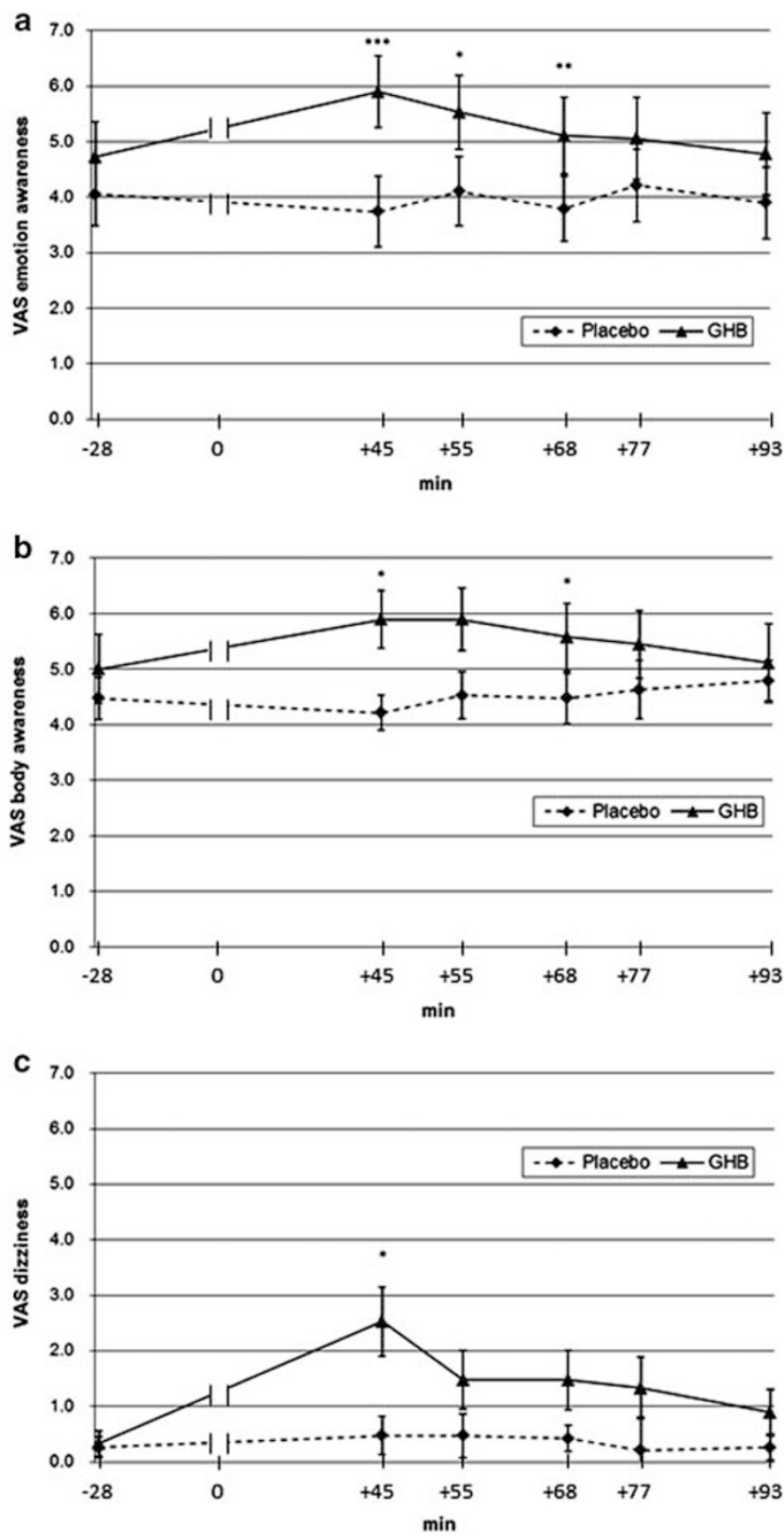

Figure 2 Effects on visual analog scale scores of gamma-hydroxybutyrate (GHB) vs placebo for (a) body awareness, (b) emotion awareness, and (c) dizziness. $* * * * 0<0.001$, $* * * 0.01$, ${ }^{*} p<0.05$ (Bonferroni-corrected).

for emotion awareness and dizziness $\left(\mathrm{F}_{5,11}=8.69-9.46\right.$, $p<0.01-0.001)$ and drug $\times$ time interactions for body and emotion awareness and dizziness $\left(\mathrm{F}_{5,11}=2.76-4.79, p<0.05-\right.$ $0.01)$. Regarding relaxation, the drug $\times$ time ANOVA showed no significant interaction. Paired $t$-tests revealed significant GHB effects for body and emotion awareness and dizziness VAS measures, compared with the placebo (body awareness +45 , +68 min, $p<0.01$; emotion awareness +45 , +55, +68 min; $p<0.01-001$; dizziness $+45, p<0.01$ ) (Figure 2).

\section{Neuroimaging}

Cerebral perfusion. We performed a whole-brain analysis for possible three-way interaction effects in a voxel-based three-way ANOVA analysis with factors scan (baseline, +40 , $+65,+85 \mathrm{~min}$ ), treatment (GHB, placebo), session ( $\mathrm{GHB}$ first, placebo first), which resulted in three regions of statistically significant changes in the bilateral ACC and the right anterior insula (Figure 3). Significant changes were also found in the right caudate nucleus $(\mathrm{rCN})$ and the right superior temporal gyrus (rSTG). However, this has to be considered with caution given that baseline $\mathrm{rCBF}$ values were significantly different in the placebo vs GHB condition in these two regions (Supplementary Figure 2).

Correlation of cerebral perfusion and subjective parameters. In the ACC and the insula, changes in the subjective effects $\left(\Delta_{-}\right.$VAS $=$VAS1 vs VAS2) were correlated with the corresponding change in the regional $\mathrm{rCBF}$ values $\left(\Delta_{-} \mathrm{CBF}\right)$ after GHB challenge. The ANCOVA model highlighted a statistically significant $(p<0.05)$ correlation between $\Delta_{-}$CBF and $\Delta_{-}$VAS for relaxation (ACC +40 , $+85 \mathrm{~min}$; insula $+85 \mathrm{~min}$; $\mathrm{rSTG}+85 \mathrm{~min}$ ), as well as body ( $\mathrm{ACC}+40,+85 \mathrm{~min}$; insula $+85 \mathrm{~min}$ ) and emotion (ACC $+40,+85 \mathrm{~min}$; insula $+85 \mathrm{~min}$ ) awareness, whereas the slope effect (ie, the interaction) was significant $(\mathrm{p}<0.05)$ for the dimension body awareness with the ACC at $+40 \mathrm{~min}$ (Figure 4) and relaxation with the insula at $+85 \mathrm{~min}$. No significant correlations or interactions were found with regard to the dizziness VAS score.

\section{DISCUSSION}

Here, we investigated the neural effects of GHB using absolute changes in rCBF. We found that $35 \mathrm{mg} / \mathrm{kg}$ (p.o.) GHB increased ratings for body and emotion awareness, conceptualized as the ability to perceive one's own feelings and physical sensations (Boden and Thompson, 2015; Cioffi, 1991), which indicated a modulation of subjective interoception and self-referential processing in healthy males. Moreover, GHB increased $\mathrm{rCBF}$ in the bilateral ACC and the right anterior insula compared with the placebo, with body and emotion awareness and relaxation but not dizziness being positively correlated with ACC and right anterior insula rCBF. In addition, positive interactions between subjective body awareness and ACC $\mathrm{rCBF}$ and between relaxation and insula $\mathrm{rCBF}$ were found. Finally, GHB compared with the placebo increased $\mathrm{rCBF}$ in the right caudate nucleus and superior temporal gyrus. However, as baseline rCBFs at both drug conditions were already significantly different in these regions, these effects should be interpreted with caution.

The exact physiological basis for neurovascular coupling, which is supposedly depicted by $\mathrm{rCBF}$ alterations, is incompletely understood (Wang et al, 2011). However, evidences point to an involvement of coordinated activities of neurons, astrocytes, and the microvasculature (Iadecola and Nedergaard, 2007). Synaptic activity due to binding to target region or downstream stimulation, triggers increases in intracellular calcium concentration in adjacent astrocytes, which lead to secretion of vasodilatatory substances that increase local blood flow (Jakovcevic and Harder, 2007). GHB mainly acts via GABA-B and partly via GHB receptors. In our participants, $\mathrm{GHB}$ increased $\mathrm{rCBF}$ in the insula and the ACC. Exclusive binding to these target regions is implausible, as both GABA-B (Billinton et al, 2000) and 

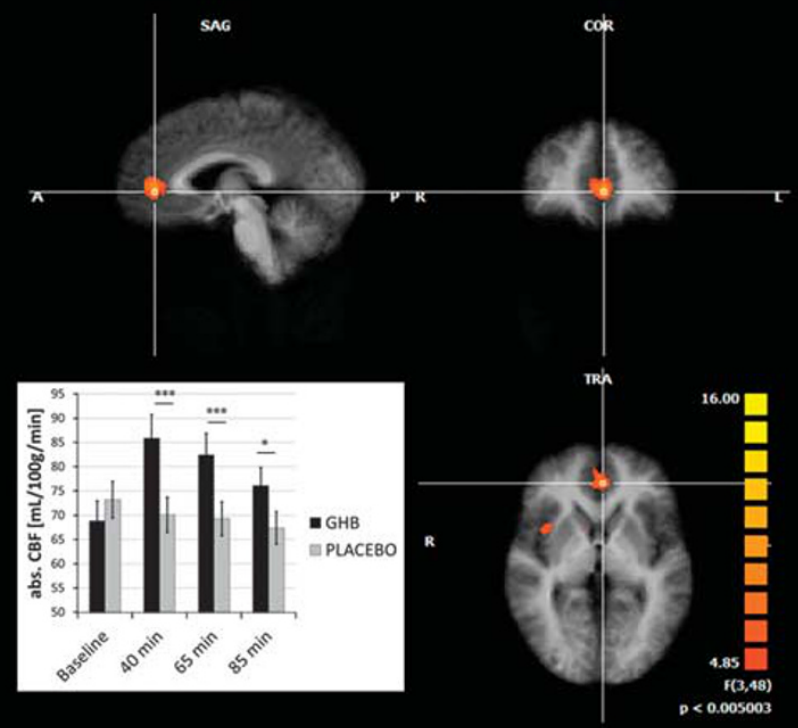

b

Insula

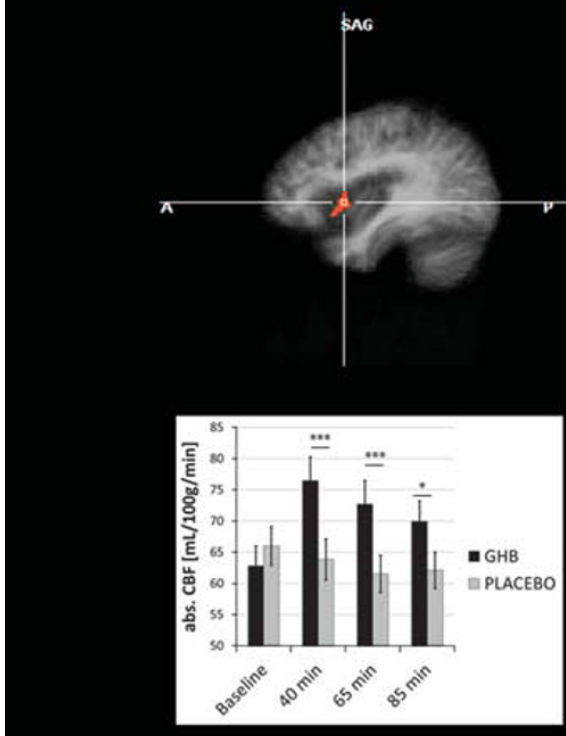

COR
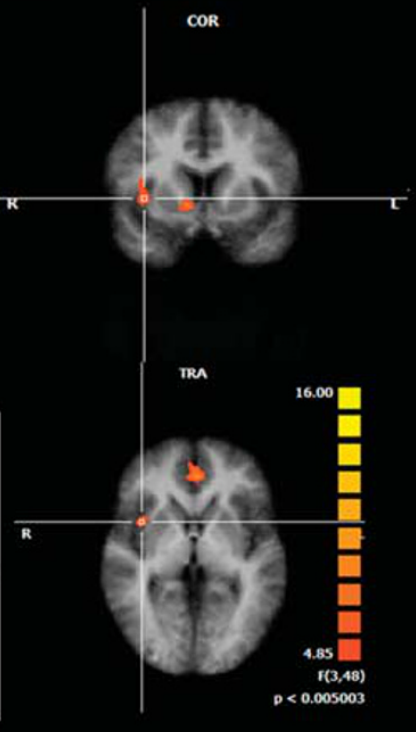

Figure 3 Whole-brain map for cerebral blood flow changes gamma-hydroxybutyrate (GHB) vs placebo with significant clusters in the (a) anterior cingulate cortex (ACC) and (b) insula, threshold $p<0.05$ (cluster-corrected) including time course of regional cerebral blood flow changes, **** $p<0.001, * p<0.05$.

GHB (Benavides et al, 1982; Gould et al, 2003) receptors have a widespread distribution throughout the brain including cortex, basal ganglia, and hippocampus. By contrast, GHB has well-documented effects on GABAergic interneurons disinhibiting mesolimbic dopamine (Cruz et al, 2004; Labouebe et al, 2007; Maitre, 1997; Pistis et al, 2005) release. These indirect dopaminergic effects lead to coordinated downstream increases in cortical activity (Crunelli et al, 2006). Hence, increased ACC and insula activity after GHB intake, which is reflected by increased $\mathrm{rCBF}$ in these regions, is most likely due to mesolimbic disinhibition via GABA-B autoreceptor-regulated interneurons. Consequently, the opposing effects of baclofen and $\mathrm{GHB}$ on the activity in the ACC and the insula are thus, most likely, due to their differential effects on mesolimbic dopamine release.

The so-called limbic system comprises several functional networks or subsystems dedicated to linking somatosensory and emotional states with cognition, emotion, and behavior (Mesulam, 2000). Derived from data in healthy subjects, a resting-state connectivity system for the integration of interoceptive information with emotional salience that forms a subjective representation of the body was located 
Bilateral Anterior Cingulate Cortex

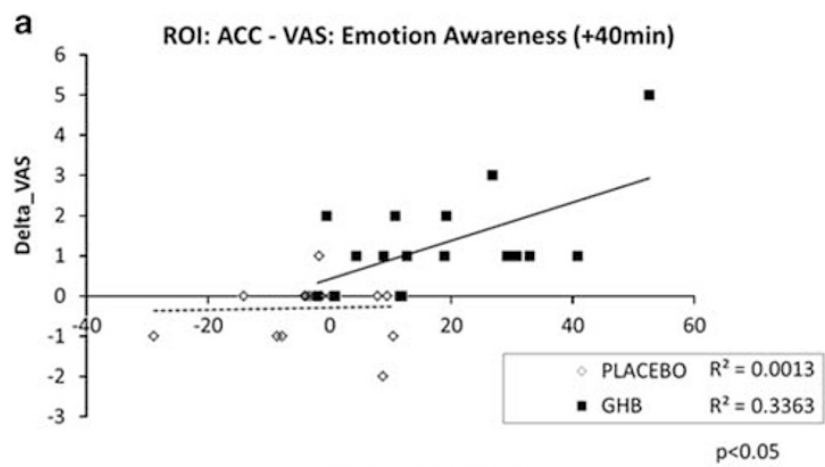

Delta_CBF $[\mathrm{ml} / \mathrm{min} / 100 \mathrm{~g}]$

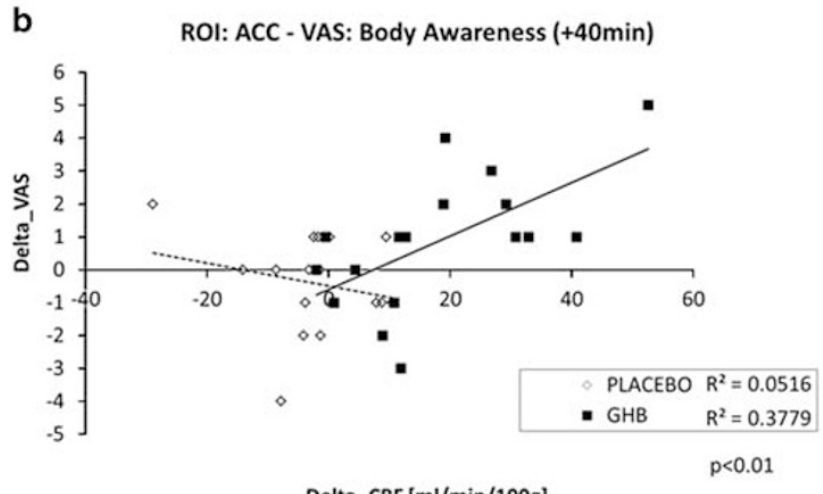

Delta_CBF $[\mathrm{ml} / \mathrm{min} / 100 \mathrm{~g}]$

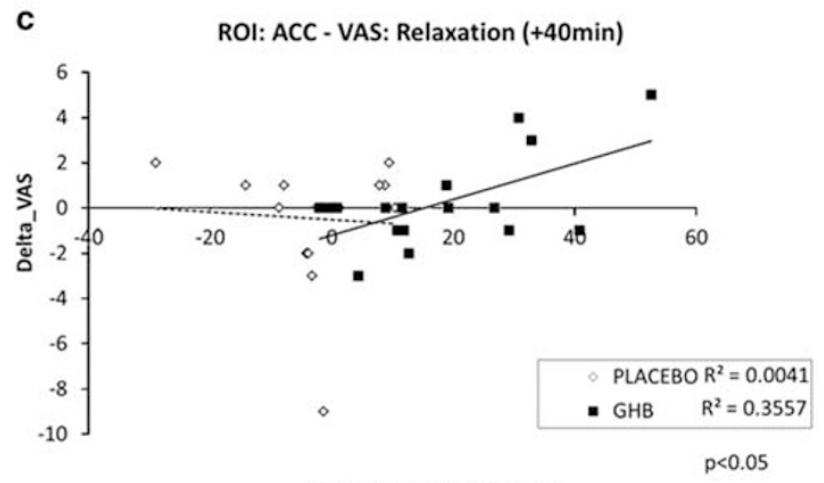

Delta_CBF $[\mathrm{ml} / \mathrm{min} / 100 \mathrm{~g}]$

\section{Right Insula}

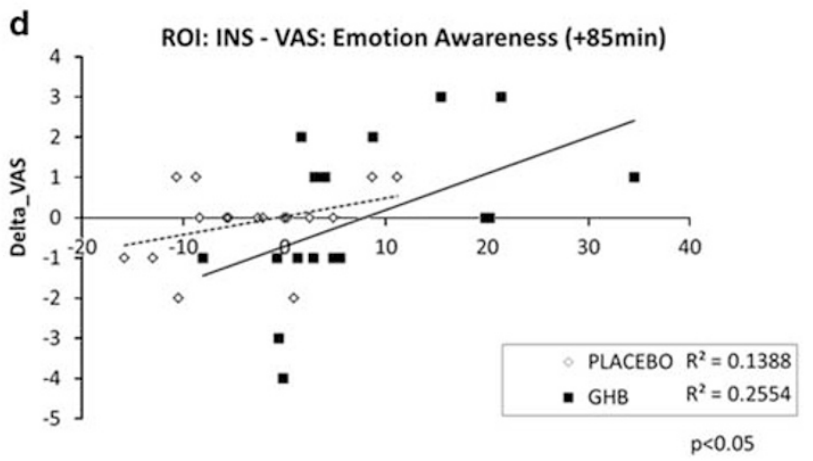

Delta_CBF $[\mathrm{ml} / \mathrm{min} / 100 \mathrm{~g}]$

e ROI: INS - VAS: Body Awareness (+85min)

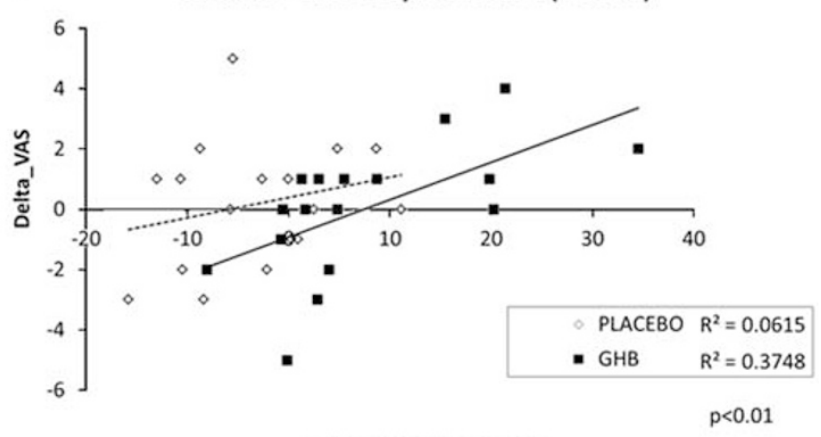

Delta_CBF $[\mathrm{ml} / \mathrm{min} / 100 \mathrm{~g}]$

f

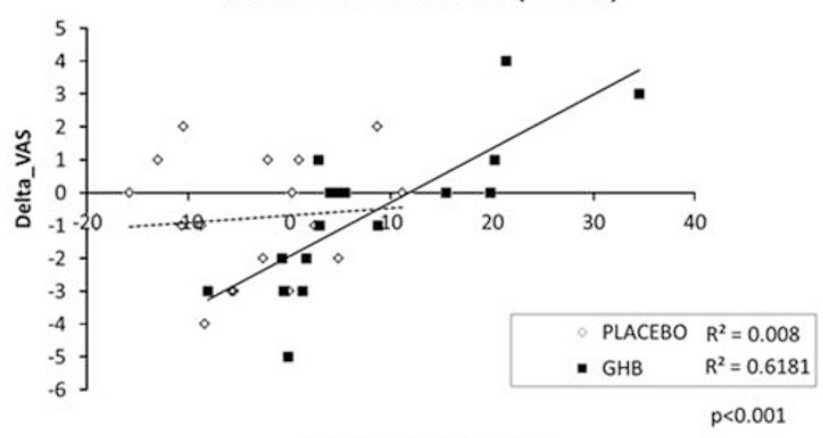

Delta_CBF $[\mathrm{ml} / \mathrm{min} / 100 \mathrm{~g}]$

Figure 4 Correlations of subjective ratings and regional cerebral blood flow, gamma-hydroxybutyrate (GHB) vs placebo (fitted lines: regression lines; all uncorrected): (a) anterior cingulate cortex (ACC) and emotion awareness ( $p<0.05)$, (b) ACC and body awareness ( $p<0.0 \mathrm{I})$, (c) ACC and relaxation $(p<0.05)$, (d) Insula and emotion awareness ( $p<0.05)$, (e) insula and body awareness $(p<0.0 \mathrm{I})$, (f) Insula and relaxation $(p<0.00 \mathrm{I})$.

between the anterior insula and parts of the anterior and mid-cingulate cortex, which are part of the limbic system (Taylor et al, 2009). A recent meta-analysis of studies assessing explicit emotion evaluation showed that the two core areas for the processing of the recognition of one's own emotional state are the ACC and the insula (Lee and Siegle, 2012). There is growing evidence that the emotional meaning of one's perceived body state is processed within the ACC, whereas non-emotional body-states are processed within the anterior insula (Smith and Lane, 2015). In our study, we found that GHB increases $\mathrm{rCBF}$ in the insula and ACC and that GHB enhances subjective body awareness by increasing cerebral perfusion in latter area. Following the argumentation of Smith and Lane (2015), this seems counterintuitive, as positive interactions of body awareness with insula $\mathrm{rCBF}$, and emotion awareness with ACC rCBF would have been expected. However, as overlapping processing of both qualities were demonstrated for the insula (Zaki et al, 2012), this might also occur in the ACC. Moreover, pleasant touch was shown to be associated with increased connectivity between the insula and the cingulate gyrus (Sailer et al, 2016) and increased activity of the ACC (Lindgren et al, 2012; Rolls et al, 2003). Interestingly, correlations of subjective parameters first occurred at $40 \mathrm{~min}$ in the ACC and only became significant in the insula at $85 \mathrm{~min}$ after GHB administration. One reason might be that the sample was underpowered, leaving the insula correlation at $40 \mathrm{~min}$ on a trend level, or that the described subjective effects 
are triggered by ACC hyperperfusion, which then lead to a top-down increase of insula susceptibility towards external stimuli.

Interestingly, GHB is illicitly used to achieve euphoria, recreation/relaxation, increased sociability, and increased sexual arousal (First et al, 2002; Luby et al, 1992; Miotto et al, 2001; Sumnall et al, 2008), which are subjective qualities that are related to above mentioned networks. In fact, we found GHB-associated increased body and emotion awareness in our healthy subjects, which were previously reported by illicit users (Barker et al, 2007; Kapitany-Foveny et al, 2015; Lee and Levounis, 2008; Sumnall et al, 2008). Intensified sensitivity towards touch and pleasure of being touched is frequently reported in this population and is probably closely linked to the prosocial and prosexual effects of the drug (Bosch et al, 2015; Bosch et al, 2017; Palamar et al, 2014; Teltzrow and Bosch, 2012). GHB effects generally peak at about $45 \mathrm{~min}$ after intake, including seemingly paradoxical effects such as sedation and stimulation (Bosch et al, 2015, 2017; Bosch and Seifritz, 2016; Liechti et al, 2016). Particularly, body awareness, emotion awareness, and dizziness also peak at the same time (Figure 2), although the co-occurrence of these effects does not necessarily imply they are strictly coupled with (or causally related between) each other. In fact, as it was evident from Figure 2, VAS score for dizziness increases steeper than VAS scores for emotion and body awareness from baseline to $45 \mathrm{~min}$ after intake and then falls back to being not significantly different from placebo at the next time point $(55 \mathrm{~min})$, whereas VAS scores for emotion and body awareness remain significantly increased compared with the placebo over several time points. Interestingly, insula-associated hyperactivation of pleasant interoceptive stimuli is a candidate biomarker for the transition to drug abuse (Migliorini et al, 2013; Stewart et al, 2015). Regarding the argumentation of Franklin et al (2011, 2012), stating that the selective GABA-B receptor agonist baclofen exerts its putative anti-craving effects via down-regulation of reward- and hedonia-associated limbic areas, such as ACC, orbitofrontal cortex, and insula, it might be assumed that the here shown ACC and insula rCBF increases could represent an abuse-promoting mechanism. However, on the one hand, GHB was also shown to have withdrawal- and craving-reducing effects in alcohol- (Leone et al, 2010) and opiate- (Gallimberti et al, 1994) dependent individuals. On the other hand, acute i.v. heroin application led to diminished rCBF in highly overlapping areas like acute baclofen (ACC, medial prefrontal cortex, and insula) (Denier et al, 2013), which challenges the dichotomy of abuse and anti-craving drugs and the assumption that these might be discernible by their effects on cerebral perfusion. As baclofen diminished $\mathrm{rCBF}$ in the medial orbitofrontal cortex, ACC, and ventral anterior insula (Franklin et al, 2012; Franklin et al, 2011), and the (dopamine D2/D3 receptor antagonist and) $\mathrm{GHB}$ receptor agonist amisulpride also reduced $\mathrm{rCBF}$ in prefrontal areas including $\mathrm{ACC}$, the here found $\mathrm{rCBF}$ increase in these areas was unexpected. Such differences are most likely due to differential effects of these drugs on mesolimbic dopamine (Cruz et al, 2004; Di Giovanni et al, 1998; Labouebe et al, 2007; Pistis et al, 2005) release and/or might be related to different pharmacokinetic and other pharmacodynamic properties, such as the rapid distribution or short elimination half-life of GHB as well as the strong
D2/D3 antagonism of amisulpride or the low to moderate affinity of baclofen to voltage-dependent calcium channels (Zvejniece et al, 2015).

Because of the above mentioned findings, impairments of interoception and self-referential processing are supposed to be related to pathological $\mathrm{rCBF}$ changes in limbic areas such as the ACC and insula, occurring in depression and other neuropsychiatric disorders. Assessment of cerebral perfusion via ASL has yielded conflicting results in depression, and no studies exist where direct associations with self-referential processing were measured. In a study, where ASL was assessed in depressed patients without measuring attentional processes, depression was associated with increased rCBF in ACC, left dorsomedial prefrontal cortex, and left subcortical areas (Duhameau et al, 2010). However, hypoperfusion of the ACC was shown in adolescent (Ho et al, 2013), adult (Ota et al, 2014) and elderly (Ishizaki et al, 2008) patients with depression, and depression severity was correlated with reduced perfusion in the default mode network (Orosz et al, 2012). Moreover, a mixed pattern with limbic hyperperfusion and prefrontal hypoperfusion was also described (Lui et al, 2009), fitting to Mayberg et al, 1999 depression model of frontocingular dysfunction based on previous positron emission tomography (PET) studies. Interestingly, a recent PET study showed differential prognostic effects of right anterior insula metabolism for the treatment response towards pharmaco- or psychotherapy in depression (McGrath et al, 2013), strengthening earlier evidences for a central role of the anterior insula in depression (Fu et al, 2013; Takahashi et al, 2010). Contrary to the heterogeneous ASL findings in depression, perception of pain is consistently associated with increased $\mathrm{rCBF}$ in the insula and other limbic areas in healthy volunteers (Maleki et al, 2013; Owen et al, 2008; Segerdahl et al, 2015) and patients, eg, with fibromyalgia (Cottam et al, 2016; Howard et al, 2012; Liu et al, 2013; Shokouhi et al, 2016). However, it seems that an increase of insula activity is not specific for pain, but rather reflects enhancement of body awareness, as it is also associated with the perception of pleasant touch (Rolls, 2015; Sailer et al, 2016). As GHB intake increases pleasure of physical contact (Teltzrow and Bosch, 2012) and enhanced emotion and body awareness in our participants, increased insular $\mathrm{rCBF}$ found in our study rather seems to reflect an affirmative mode of self-reference. GHB was demonstrated to be an effective treatment for binge-eating disorder (McElroy et al, 2011) and fibromyalgia (Spaeth et al, 2012), and was proposed as an experimental therapeutic in depression (Bosch et al, 2012; Mamelak, 2009). Enhancement of interoception and emotional self-referential processes via $\mathrm{ACC}$ and right anterior insula $\mathrm{rCBF}$ increase might be a useful diagnostic and/or therapeutic biomarker in these conditions.

Our study bears a number of limitations: GHB plasma levels were not assessed and therefore individual differences, eg, due to individual metabolic patterns or not permitted food intake cannot be ruled out completely. Moreover, effectivity of blinding was not systematically assessed, and questionable due to recognizable subjective drug effects. Finally, body and emotion awareness was assessed using VAS, which means these effects reflect the subjective impression of one's own awareness. In future studies, GHB plasma levels should be assessed, the use of an active placebo 
should be considered to reduce probability of unblinding, and additional experimental paradigms should be employed to investigate in more detail body and emotion awareness.

In summary, our main finding is that GHB enhanced body and emotion awareness, defined as the ability to perceive one's own feelings and physical sensations, and increased $\mathrm{rCBF}$ in the ACC and right anterior insula in healthy male volunteers. These effects were positively correlated with each other. In terms of interaction, GHB-induced body awareness was accompanied by increased ACC rCBF, whereas relaxation under GHB was accompanied by increased insular rCBF. The time course of the effects suggests a possible initiation of the subjective effects via $\mathrm{rCBF}$ increase in the ACC and a consecutive top-down enhancement of insular susceptibility for external stimuli. It is likely that this interaction reflects a primary high-level enhancement of the emotional meaning of the subjects' perceived body state, which has implications for the understanding of motivations of drug use, as well as for the modulation of interoception and self-referential processes in patients with affective disorders. As such, we suggest GHB to be a candidate medication for personalized treatment of depression for selected patients and with specific indications.

\section{FUNDING AND DISCLOSURE}

Dr Seifritz's work has been funded by the University of Zürich and the Swiss National Science Foundation. He has received compensation as a member of the scientific advisory boards of Lundbeck, Otsuka, Janssen, Eli Lilly, and Takeda. He gave scientific talks in symposia financed by Eli Lilly, Astra Zeneca, and Janssen. Dr Quednow was supported by grants from the Swiss National Science Foundation (SNSF; Grant Nos. PP00P1-123516/1 and PP00P1-146326/1) and has received a speaker's fee for a talk from Lundbeck. Dr Bosch, Dr Esposito, Mr von Rotz, Mr Dornbierer, and Dr Staempfli declare no conflict of interest. Dr Havranek has equity interest in Schweizerische Gesellschaft für Gesundheitssystemforschung (SGGF).

\section{ACKNOWLEDGMENTS}

We would like to thank Sara Romer, Dr Milan Scheidegger, and Dr Rainer Krähenmann for their helpful assistance in data collection, scientific discussion, and subject recruitment.

\section{REFERENCES}

Abanades S, Farre M, Segura M, Pichini S, Barral D, Pacifici R et al (2006). Gamma-hydroxybutyrate (GHB) in humans: pharmacodynamics and pharmacokinetics. Ann N Y Acad Sci 1074: 559-576.

Agabio R, Preti A, Gessa GL (2013). Efficacy and tolerability of baclofen in substance use disorders: a systematic review. Eur Addic Res 19: 325-345.

Alsop DC, Detre JA, Golay X, Gunther M, Hendrikse J, HernandezGarcia L et al (2015). Recommended implementation of arterial spin-labeled perfusion MRI for clinical applications: a consensus of the ISMRM perfusion study group and the European consortium for ASL in dementia. Magn Reson Med 73: 102-116.

Andresen H, Aydin BE, Mueller A, Iwersen-Bergmann S (2011). An overview of gamma-hydroxybutyric acid: pharmacodynamics, pharmacokinetics, toxic effects, addiction, analytical methods, and interpretation of results. Drug Test Anal 3: 560-568.

Barker JC, Harris SL, Dyer JE (2007). Experiences of gamma hydroxybutyrate (GHB) ingestion: a focus group study. J Psychoactive Drugs 39: 115-129.

Benavides J, Rumigny JF, Bourguignon JJ, Cash C, Wermuth CG, Mandel $\mathrm{P}$ et al (1982). High affinity binding sites for gammahydroxybutyric acid in rat brain. Life Sci 30: 953-961.

Billinton A, Ige AO, Wise A, White JH, Disney GH, Marshall FH et al (2000). GABA(B) receptor heterodimer-component localisation in human brain. Brain Res Mol Brain Res 77: 111-124.

Boden MT, Thompson RJ (2015). Facets of emotional awareness and associations with emotion regulation and depression. Emotion 15: 399-410.

Bosch OG, Eisenegger C, Gertsch J, von Rotz R, Dornbierer D, Gachet MS et al (2015). Gamma-hydroxybutyrate enhances mood and prosocial behavior without affecting plasma oxytocin and testosterone. Psychoneuroendocrinology 62: 1-10.

Bosch OG, Havranek MM, Baumberger A, Preller KH, von Rotz R, Herdener $M$ et al (2017). Neural underpinnings of prosexual effects induced by gamma-hydroxybutyrate in healthy male humans. Eur Neuropsychopharmacol 27: 372-382.

Bosch OG, Quednow BB, Seifritz E, Wetter TC (2012). Reconsidering GHB: orphan drug or new model antidepressant? J Psychopharmacol 26: 618-628.

Bosch OG, Seifritz E (2016). The behavioural profile of gammahydroxybutyrate, gamma-butyrolactone and 1,4-butanediol in humans. Brain Res Bull 47: 47-60.

Buxton RB, Frank LR, Wong EC, Siewert B, Warach S, Edelman RR (1998). A general kinetic model for quantitative perfusion imaging with arterial spin labeling. Magn Reson Med 40: 383-396.

Carter LP, Koek W, France CP (2009). Behavioral analyses of GHB: receptor mechanisms. Pharmacol Therap 121: 100-114.

Chen Y, Wan HI, O'Reardon JP, Wang DJ, Wang Z, Korczykowski M et al (2011). Quantification of cerebral blood flow as biomarker of drug effect: arterial spin labeling phMRI after a single dose of oral citalopram. Clin Pharmacol Therap 89: 251-258.

Cioffi D (1991). Beyond attentional strategies: cognitive-perceptual model of somatic interpretation. Psychol Bull 109: 25-41.

Cottam WJ, Condon L, Alshuft H, Reckziegel D, Auer DP (2016). Associations of limbic-affective brain activity and severity of ongoing chronic arthritis pain are explained by trait anxiety. NeuroImage Clin 12: 269-276.

Crunelli V, Emri Z, Leresche N (2006). Unravelling the brain targets of gamma-hydroxybutyric acid. Curr Opin Pharmacol 6: 44-52.

Cruz HG, Ivanova T, Lunn ML, Stoffel M, Slesinger PA, Luscher C (2004). Bi-directional effects of GABA(B) receptor agonists on the mesolimbic dopamine system. Nat Neurosci 7: 153-159.

Dai W, Garcia D, de Bazelaire C, Alsop DC (2008). Continuous flow-driven inversion for arterial spin labeling using pulsed radio frequency and gradient fields. Magn Reson Med 60: 1488-1497.

Denier N, Gerber H, Vogel M, Klarhofer M, Riecher-Rossler A, Wiesbeck GA et al (2013). Reduction in cerebral perfusion after heroin administration: a resting state arterial spin labeling study. PLoS ONE 8: e71461.

Detre JA, Wang J, Wang Z, Rao H (2009). Arterial spin-labeled perfusion MRI in basic and clinical neuroscience. Curr Opin Neurol 22: 348-355.

Di Giovanni G, Di Mascio M, Di Matteo V, Esposito E (1998). Effects of acute and repeated administration of amisulpride, a dopamine D2/D3 receptor antagonist, on the electrical activity of midbrain dopaminergic neurons. J Pharmacol Exp Therap 287: 51-57.

Duhameau B, Ferre JC, Jannin P, Gauvrit JY, Verin M, Millet B et al (2010). Chronic and treatment-resistant depression: a study using arterial spin labeling perfusion MRI at 3Tesla. Psychiatry Res 182: $111-116$. 
Engberg G, Nissbrandt H (1993). Gamma-Hydroxybutyric acid (GHBA) induces pacemaker activity and inhibition of substantia nigra dopamine neurons by activating GABAB-receptors. Naunyn Schmiedebergs Arch Pharmacol 348: 491-497.

First MB, Spitzer RL, Gibbon M, Williams JBW (2002). Structured Clinical Interview for DSM-IV-TR Axis I Disorders, Research Version, Non-Patient. Biometrics Research, New York State Psychiatric Institute: New York.

Forman SD, Cohen JD, Fitzgerald M, Eddy WF, Mintun MA, Noll DC (1995). Improved assessment of significant activation in functional magnetic resonance imaging (fMRI): use of a clustersize threshold. Magn Reson Med 33: 636-647.

Franklin TR, Shin J, Jagannathan K, Suh JJ, Detre JA, O'Brien CP et al (2012). Acute baclofen diminishes resting baseline blood flow to limbic structures: a perfusion fMRI study. Drug Alcohol Depend 125: 60-66.

Franklin TR, Wang Z, Sciortino N, Harper D, Li Y, Hakun J et al (2011). Modulation of resting brain cerebral blood flow by the GABA B agonist, baclofen: a longitudinal perfusion fMRI study. Drug Alcohol Depend 117: 176-183.

Fu CH, Steiner H, Costafreda SG (2013). Predictive neural biomarkers of clinical response in depression: a meta-analysis of functional and structural neuroimaging studies of pharmacological and psychological therapies. Neurobiol Dis 52: 75-83.

Gallimberti L, Schifano F, Forza G, Miconi L, Ferrara SD (1994). Clinical efficacy of gamma-hydroxybutyric acid in treatment of opiate withdrawal. Eur Arch Psychiatry Clin Neurosci 244: 113-114.

Gould GG, Mehta AK, Frazer A, Ticku MK (2003). Quantitative autoradiographic analysis of the new radioligand $[(3) \mathrm{H}](2 \mathrm{E})$ (5-hydroxy-5,7,8,9-tetrahydro-6H-benzo[a][7]annulen-6-ylidene) ethanoic acid ([(3)H]NCS-382) at gamma-hydroxybutyric acid (GHB) binding sites in rat brain. Brain Res 979: 51-56.

Gould T, Chen L, Emri Z, Pirttimaki T, Errington AC, Crunelli V et al (2014). GABA(B) receptor-mediated activation of astrocytes by gamma-hydroxybutyric acid. Philos Trans $R$ Soc Lond B Biol Sci 369: 20130607.

Harshaw C (2015). Interoceptive dysfunction: toward an integrated framework for understanding somatic and affective disturbance in depression. Psychol Bull 141: 311-363.

Ho TC, Wu J, Shin DD, Liu TT, Tapert SF, Yang G et al (2013). Altered cerebral perfusion in executive, affective, and motor networks during adolescent depression. J Am Acad Child Adolesc Psychiatry 52: 1076-1091 e1072.

Howard MA, Sanders D, Krause K, O'Muircheartaigh J, Fotopoulou A, Zelaya F et al (2012). Alterations in resting-state regional cerebral blood flow demonstrate ongoing pain in osteoarthritis: an arterial spin-labeled magnetic resonance imaging study. Arthritis Rheum 64: 3936-3946.

Iadecola C, Nedergaard M (2007). Glial regulation of the cerebral microvasculature. Nat Neurosci 10: 1369-1376.

Ishizaki J, Yamamoto H, Takahashi T, Takeda M, Yano M, Mimura $M$ (2008). Changes in regional cerebral blood flow following antidepressant treatment in late-life depression. Int $J$ Geriatr Psychiatry 23: 805-811.

Jakovcevic D, Harder DR (2007). Role of astrocytes in matching blood flow to neuronal activity. Curr Top Dev Biol 79: 75-97.

Kapitany-Foveny M, Mervo B, Corazza O, Kokonyei G, Farkas J, Urban R et al (2015). Enhancing sexual desire and experience: an investigation of the sexual correlates of gamma-hydroxybutyrate (GHB) use. Hum Psychopharmacol 30: 276-284.

Labouebe G, Lomazzi M, Cruz HG, Creton C, Lujan R, Li M et al (2007). RGS2 modulates coupling between GABAB receptors and GIRK channels in dopamine neurons of the ventral tegmental area. Nat Neurosci 10: 1559-1568.

Lee KH, Siegle GJ (2012). Common and distinct brain networks underlying explicit emotional evaluation: a meta-analytic study. Soc Cogn Affect Neurosci 7: 521-534.
Lee SJ, Levounis P (2008). Gamma hydroxybutyrate: an ethnographic study of recreational use and abuse. J Psychoactive Drugs 40: $245-253$.

Lehrl S (2005). Mehrfachwahl-Wortschatz-Intelligenztest: MWT-B. Spitta-Verl.: Balingen.

Leone MA, Vigna-Taglianti F, Avanzi G, Brambilla R, Faggiano F (2010). Gamma-hydroxybutyrate (GHB) for treatment of alcohol withdrawal and prevention of relapses. Cochrane Database Syst Rev 2: CD006266.

Liechti ME, Quednow BB, Liakoni E, Dornbierer D, von Rotz R, Gachet MS et al (2016). Pharmacokinetics and pharmacodynamics of gamma-hydroxybutyrate in healthy subjects. $\mathrm{Br} J$ Clin Pharmacol 81: 980-988.

Lindgren L, Westling G, Brulin C, Lehtipalo S, Andersson M, Nyberg L (2012). Pleasant human touch is represented in pregenual anterior cingulate cortex. NeuroImage 59: 3427-3432.

Liu J, Hao Y, Du M, Wang X, Zhang J, Manor B et al (2013). Quantitative cerebral blood flow mapping and functional connectivity of postherpetic neuralgia pain: a perfusion fMRI study. Pain 154: $110-118$.

Luby S, Jones J, Zalewski A (1992). GHB use in South Carolina. Am J Public Health 82: 128.

Lui S, Parkes LM, Huang X, Zou K, Chan RC, Yang $\mathrm{H}$ et al (2009). Depressive disorders: focally altered cerebral perfusion measured with arterial spin-labeling MR imaging. Radiology 251: 476-484.

Maitre M (1997). The gamma-hydroxybutyrate signalling system in brain: organization and functional implications. Prog Neurobiol 51: 337-361.

Maitre M, Ratomponirina C, Gobaille S, Hode Y, Hechler V (1994). Displacement of $[3 \mathrm{H}]$ gamma-hydroxybutyrate binding by benzamide neuroleptics and prochlorperazine but not by other antipsychotics. Eur J Pharmacol 256: 211-214.

Maleki N, Brawn J, Barmettler G, Borsook D, Becerra L (2013). Pain response measured with arterial spin labeling. NMR Biomed 26: 664-673.

Mamelak M (2009). Narcolepsy and depression and the neurobiology of gammahydroxybutyrate. Prog Neurobiol 89: 193-219.

Mayberg HS, Liotti M, Brannan SK, McGinnis S, Mahurin RK, Jerabek PA et al (1999). Reciprocal limbic-cortical function and negative mood: converging PET findings in depression and normal sadness. Am J Psychiatry 156: 675-682.

McElroy SL, Guerdjikova AI, Winstanley EL, O'Melia AM, Mori N, Keck PE Jr. et al (2011). Sodium oxybate in the treatment of binge eating disorder: an open-label, prospective study. Int J Eat Disord 44: $262-268$.

McGrath CL, Kelley ME, Holtzheimer PE, Dunlop BW, Craighead WE, Franco AR et al (2013). Toward a neuroimaging treatment selection biomarker for major depressive disorder. JAMA Psychiatry 70: 821-829.

Mesulam M (2000). Behavioural neuroanatomy: large-scale networks, association cortex, frontal syndromes, the limbic system, and the hemispheric specializations. In: Mesulam M (ed). Principles of Behavioural and Cognitive Neurology. Oxford University Press: Oxford.

Migliorini R, Stewart JL, May AC, Tapert SF, Paulus MP (2013). What do you feel? Adolescent drug and alcohol users show altered brain response to pleasant interoceptive stimuli. Drug Alcohol Depend 133: 661-668.

Miotto K, Darakjian J, Basch J, Murray S, Zogg J, Rawson R (2001). Gamma-hydroxybutyric acid: patterns of use, effects and withdrawal. Am J Addict 10: 232-241.

Nasrallah FA, Maher AD, Hanrahan JR, Balcar VJ, Rae CD (2010). gamma-Hydroxybutyrate and the GABAergic footprint: a metabolomic approach to unpicking the actions of GHB. J Neurochem 115: $58-67$.

Orosz A, Jann K, Federspiel A, Horn H, Hofle O, Dierks T et al (2012). Reduced cerebral blood flow within the default-mode 
network and within total gray matter in major depression. Brain Connect 2: 303-310.

Ota M, Noda T, Sato N, Hattori K, Teraishi T, Hori H et al (2014). Characteristic distributions of regional cerebral blood flow changes in major depressive disorder patients: a pseudo-continuous arterial spin labeling (pCASL) study. J Affect Disord 165: 59-63.

Owen DG, Bureau Y, Thomas AW, Prato FS, St Lawrence KS (2008). Quantification of pain-induced changes in cerebral blood flow by perfusion MRI. Pain 136: 85-96.

Palamar JJ, Kiang MV, Storholm ED, Halkitis PN (2014). A qualitative descriptive study of perceived sexual effects of club drug use in gay and bisexual men. Psychol Sex 5: 143-160.

Papp M, Wieronska J (2000). Antidepressant-like activity of amisulpride in two animal models of depression. J Psychopharmacol 14: 46-52.

Paulus MP, Stein MB (2010). Interoception in anxiety and depression. Brain Struct Funct 214: 451-463.

Perrault G, Depoortere R, Morel E, Sanger DJ, Scatton B (1997). Psychopharmacological profile of amisulpride: an antipsychotic drug with presynaptic D2/D3 dopamine receptor antagonist activity and limbic selectivity. J Pharmacol Exp Therap 280: 73-82.

Pistis M, Muntoni AL, Pillolla G, Perra S, Cignarella G, Melis M et al (2005). Gamma-hydroxybutyric acid (GHB) and the mesoaccumbens reward circuit: evidence for $\mathrm{GABA}(\mathrm{B})$ receptor-mediated effects. Neuroscience 131: 465-474.

Quednow BB, Kuhn KU, Hoenig K, Maier W, Wagner M (2004). Prepulse inhibition and habituation of acoustic startle response in male MDMA ('ecstasy') users, cannabis users, and healthy controls. Neuropsychopharmacology 29: 982-990.

Racagni G, Canonico PL, Ravizza L, Pani L, Amore M (2004). Consensus on the use of substituted benzamides in psychiatric patients. Neuropsychobiology 50: 134-143.

Rolls ET (2015). Limbic systems for emotion and for memory, but no single limbic system. Cortex 62: 119-157.

Rolls ET, O'Doherty J, Kringelbach ML, Francis S, Bowtell R, McGlone F (2003). Representations of pleasant and painful touch in the human orbitofrontal and cingulate cortices. Cereb Cortex 13: $308-317$.

Sailer U, Triscoli C, Haggblad G, Hamilton P, Olausson H, Croy I (2016). Temporal dynamics of brain activation during 40 minutes of pleasant touch. NeuroImage 139: 360-367.

Saleem P, Olie JP, Loo H (2002). Social functioning and quality of life in the schizophrenic patient: advantages of amisulpride. Int Clin Psychopharmacol 17: 1-8.

Salmeron BJ, Stein EA (2002). Pharmacological applications of magnetic resonance imaging. Psychopharmacol Bull 36: 102-129.

Schmidt CF, Degonda N, Luechinger R, Henke K, Boesiger P (2005). Sensitivity-encoded (SENSE) echo planar fMRI at 3T in the medial temporal lobe. NeuroImage 25: 625-641.

Segerdahl AR, Mezue M, Okell TW, Farrar JT, Tracey I (2015). The dorsal posterior insula subserves a fundamental role in human pain. Nat Neurosci 18: 499-500.

Shokouhi M, Davis KD, Moulin DE, Morley-Forster P, Nielson WR, Bureau $Y$ et al (2016). Basal ganglia perfusion in fibromyalgia is related to pain disability and disease impact: an arterial spin labeling study. Clin J Pain 32: 495-505.

Smith R, Lane RD (2015). The neural basis of one's own conscious and unconscious emotional states. Neurosci Biobehav Rev 57: $1-29$.

Snead OC 3rd (2000). Evidence for a G protein-coupled gammahydroxybutyric acid receptor. J Neurochem 75: 1986-1996.

Spaeth M, Bennett RM, Benson BA, Wang YG, Lai C, Choy EH (2012). Sodium oxybate therapy provides multidimensional improvement in fibromyalgia: results of an international phase 3 trial. Ann Rheum Dis 71: 935-942.

Stewart JL, May AC, Tapert SF, Paulus MP (2015). Hyperactivation to pleasant interoceptive stimuli characterizes the transition to stimulant addiction. Drug Alcohol Depend 154: 264-270.

Sumnall HR, Woolfall K, Edwards S, Cole JC, Beynon CM (2008). Use, function, and subjective experiences of gamma-hydroxybutyrate (GHB). Drug Alcohol Depend 92: 286-290.

Takahashi T, Yucel M, Lorenzetti V, Tanino R, Whittle S, Suzuki M et al (2010). Volumetric MRI study of the insular cortex in individuals with current and past major depression. J Affect Disord 121: 231-238.

Taylor KS, Seminowicz DA, Davis KD (2009). Two systems of resting state connectivity between the insula and cingulate cortex. Hum Brain Map 30: 2731-2745.

Teltzrow R, Bosch OG (2012). Ecstatic anaesthesia: Ketamine and GHB between medical use and self-experimentation. Appl Cardiopulm Pathophysiol 16: 309-321.

Thai D, Dyer JE, Jacob P, Haller CA (2007). Clinical pharmacology of 1,4-butanediol and gamma-hydroxybutyrate after oral 1,4-butanediol administration to healthy volunteers. Clin Pharmacol Therap 81: 178-184.

Viviani R, Graf H, Wiegers M, Abler B (2013). Effects of amisulpride on human resting cerebral perfusion. Psychopharmacology 229: 95-103.

Wang DJ, Chen Y, Fernandez-Seara MA, Detre JA (2011). Potentials and challenges for arterial spin labeling in pharmacological magnetic resonance imaging. J Pharmacol Exp Therap 337: 359-366.

Wiebking C, de Greck M, Duncan NW, Tempelmann C, Bajbouj M, Northoff G (2015). Interoception in insula subregions as a possible state marker for depression-an exploratory fMRI study investigating healthy, depressed and remitted participants. Front Behav Neurosci 9: 82.

Zaki J, Davis JI, Ochsner KN (2012). Overlapping activity in anterior insula during interoception and emotional experience. NeuroImage 62: 493-499.

Zerbib R, Pierrefiche G, Ferran C, Laborit T (1992). Potential antidepressant activity of gamma-hydroxybutyrate in the mouse 'behavioral despair' test: correlation with the central dopaminergic system. Res Commun Psychol Psychiat Behav 17: 109-122.

Zvejniece L, Vavers E, Svalbe B, Veinberg G, Rizhanova K, Liepins V et al (2015). R-phenibut binds to the alpha2-delta subunit of voltage-dependent calcium channels and exerts gabapentin-like anti-nociceptive effects. Pharmacol Biochem Behav 137: 23-29.

Supplementary Information accompanies the paper on the Neuropsychopharmacology website (http://www.nature.com/npp) 